\title{
Extra-articular osteochondromatosis: A collection of four clinical cases of different localization
}

\author{
Anna Caruso, Riccardo La Macchia, Sana Boudabbous \\ Radiology Department, Geneva University Hospital, Switzerland
}

Received: January 9, 2018

Accepted: March 22, 2018

DOI: $10.5430 /$ jst.v8n2p1

URL: http://dx.doi.org/10.5430/jst.v8n2p1

\begin{abstract}
Synovial chondromatosis is known to be frequently intra-articular and more rarely extra-articular. We present four cases of extra-articular chondromatosis in four different localizations: in the retro-olecranon bursa, in the sheath of the flexor of hallucis longus muscle, in the extra-synovial space of the knee and within the muscle's fibers of brachialis muscle. Plain radiography, ultrasonography, tomodensitometry and magnetic resonance imaging show imaging characteristics, which help in differential diagnosis. Surgical excision is the gold standard treatment to avoid recurrence or malignancy transformation and to achieve a normal articular mobility.
\end{abstract}

Key Words: Extra-articular osteochondromatosis, Neoplasms, Elbow, Ankle, Knee

\section{INTRODUCTION}

Synovial chondromatosis is an uncommon condition characterized by the cartilaginous metaplasia of synovial membrane causing the formation of cartilaginous nodules. ${ }^{[1]}$ Synovial chondromatosis can be intra-articular or extra-articular according if these nodules, even calcified or not, are extruded in the synovial joint or in the tendon sheaths and bursae. ${ }^{[2]}$ Intra-articular synovial osteochondromatosis usually affect one articulation and commonly involved the knee. Less frequently, other joints affected are shoulder, acromioclavicular, elbow, wrist and interphalangeal joints. ${ }^{[3]}$ Extra-articular osteochondromatosis is rare and it affects mainly tendon sheaths and the bursa of wrist, fingers and feet. ${ }^{[4]}$ We describe through four cases, this rare condition in four different localizations.

\section{CASE RePORtS}

\subsection{Case 1}

A 74 years old female presented to the Department of Orthopedics, complaining of an exudation associated with an ulceration of a swelling mass of the right elbow. The swelling mass has been already diagnosed 15 years previously and has been followed over the years without any kind of complication neither any symptomatology. The patient had no medical history of gouts neither of injury. In the physical examination, no limited motion was observed either any nervous deficit. The swelling mass was localized over the dorsal side of the right elbow. The exudation resembles a chalky substance, similar to the urate monosodium crystals of tophi.

Plain radiographs showed multiple calcified bodies gathered in a huge mass on the posterior side of the proximal ulnar metaphyse, without bone lysis (see Figure 1).

*Correspondence: Anna Caruso; Email: anna.caruso@ hcuge.ch; Address: Radiology Department, Geneva University Hospital, Switzerland. 


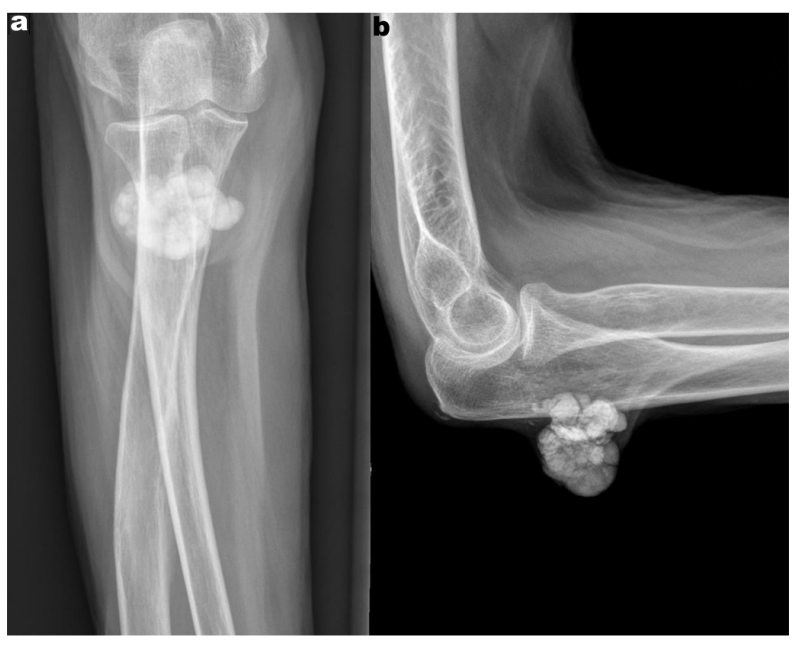

Figure 1. A 74 years old female complaining of an exudation associated with an ulceration of a swelling mass of the right elbow. Anteroposterior (a) and lateral (b) X-rays show a mass composed of multiple radiopaque bodies on the posterior side of the proximal ulnar metaphyse

Computed tomography (CT) revealed a calcified density mass with a double component, dense and amorphous without tissue component. It confirmed the absence of lysis in addition to an advanced arthropathy (see Figure 2).

Magnetic resonance imaging (MRI) was performed to evaluate the extension of the disease and the relationship with surrounding tissues. Axial and sagittal T1 and sagittal T2 weighted images showed a low-intensity multiples rounded bodies of different sizes, localized in the retro-olecranon bursa. The bursa's wall were thick and of high-signal intensity. T2-Gradient Echo weighted images with fat suppression also showed low-signal intensity. No foreign body was situated in capsular cavity (see Figure 3 ).

A surgical excision was decided. With the help of an axillary blockage, posterior surgical access to the elbow and a total removal of the calcified bodies were performed. Histopathologic exam confirmed cartilaginous nature of bodies with peripheric gigantocellular reaction and metaplastic fibrocartilaginous foci. The excision margins were free of pathology. The patient discharged without complication. No recurrence was occurred in the post- operative follow-up.

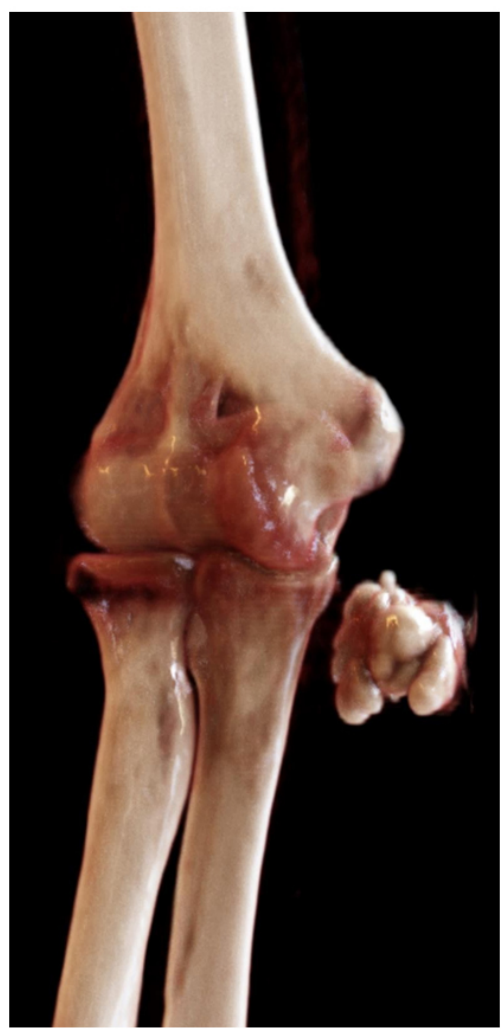

Figure 2. Cinematic 3D volume rendering CT revealed an amorphic and dense component composing the mass. No lysis is shown

Figure 3. Sagittal T1 (a), sagittal PDFS (b) and axial PDFS (c) images showed a low-intensity multiples rounded bodies of different sizes, localized in the retro-olecranon bursa

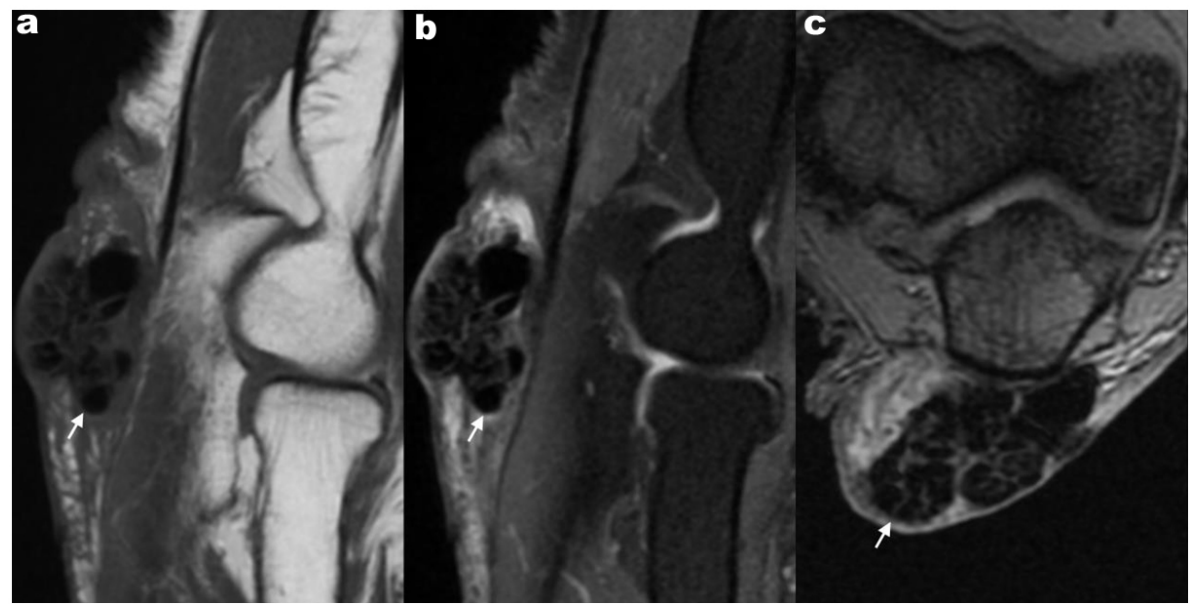




\subsection{Case 2}

A 47-year-old male patient presented to our hospital complaining about pain and swelling of his left ankle in result of a fall down from the stairs. He had a history of ankle's instability from couple of years associated with an impression of subluxation in maximum amplitudes of motion. Physical examination revealed swelling of external malleolus and a firm mass in the posterior talocrural joint. Tests for the instability were positives. Plain radiography of left ankle showed a radio-opaque mass composed of multiple calcified bodies along the flexor hallucis longus sheath tendon (see Figure 4a). CT showed soft tissue infiltration and an irregular mass with multiples osseous loose bodies inside the sheath of the flexor of hallucis longus muscle. Other findings of bone avulsion in medial malleolus and the antero-medial aspect of the talus as in the sulcus calcanei referred to an ancient injury, in addition to talocrural arthrosis (see Figure 4 b,c).

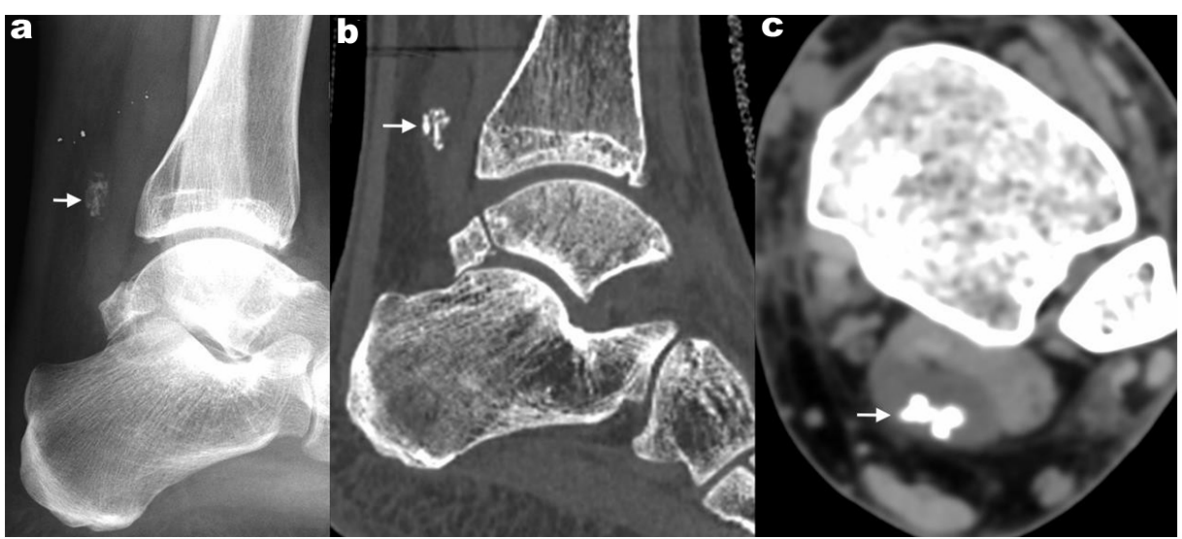

Figure 4. Lateral plain radiography (a) shows multiple calcified bodies along the flexor hallucis longus sheath tendon (white arrow). CT in sagittal bone reconstruction (b) and axial soft tissue reconstruction (c) confirm the location of calcifications and reveal the association of soft tissues effusion (white arrows)

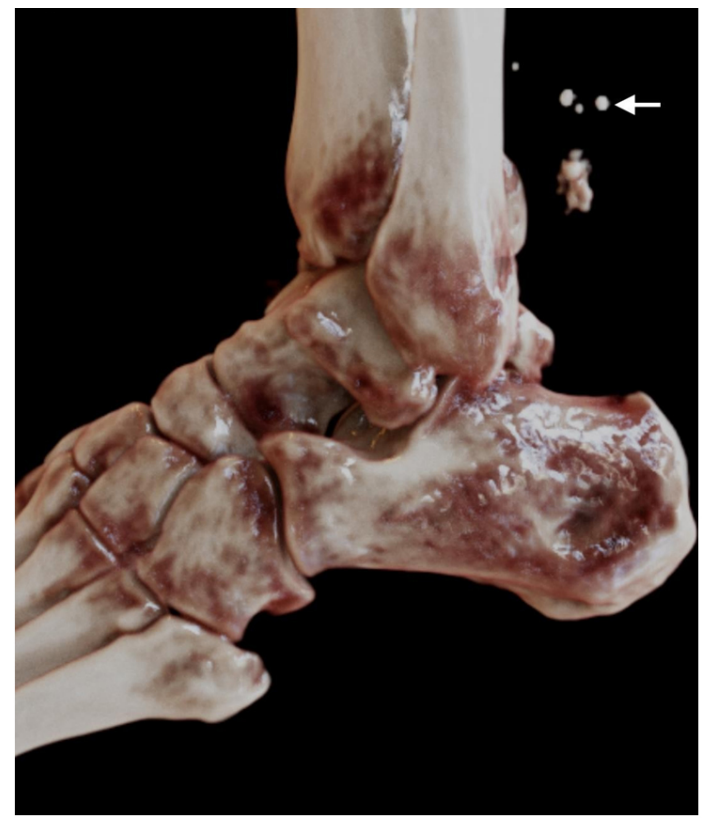

Figure 5. Cinematic 3D Volume rendering CT showing the presence of metallic foreign bodies in the soft- tissues of the posterior side of the ankle (white arrow)

The presence of metallic foreign bodies (see Figure 5) in the soft-tissues of the ankle interdicted fulfillment of an MRI. No surgical excision was accomplished since symptoms were in regression and pain in relief after drug administration as an improvement of mobility after three cycles of physiotherapy. Clinical follow-up is carried out every three months without alteration.

\subsection{Case 3}

A 49 years old female patient presented to the Emergency Department in consequence of a traumatic sprain of the left ankle with landing on the knees. On physical examination, in addition to a hematoma, a swelling and painful mass was located in the external side of the distal metaphysis of femur. Mobility was preserved without sensitive troubles. Plain radiography revealed an amorphous calcification with indefinite contours on the lateral aspect of the distal metaphysis of femur (see Figure 6).

T1 and T2-weighted images in axial and sagittal sequences showed a low-intensity central calcified mass of $26 \mathrm{~mm}$ with a peripheric ring of $6 \mathrm{~mm}$ in thickness in high-intensity on T2 weighted image, localized in extra- synovial space (see Figure 7).

Furthermore, MRI did not reveal any feature of arthropathy. The patient refused the surgical excision and she is clinically followed every three months. 
Figure 6. A 49 years old female patient presented a swelling and painful mass located in the external side of the distal metaphysis of femur. Anteroposterior (a) and lateral (b) $\mathrm{X}$-rays showed the presence of an amorphous calcification

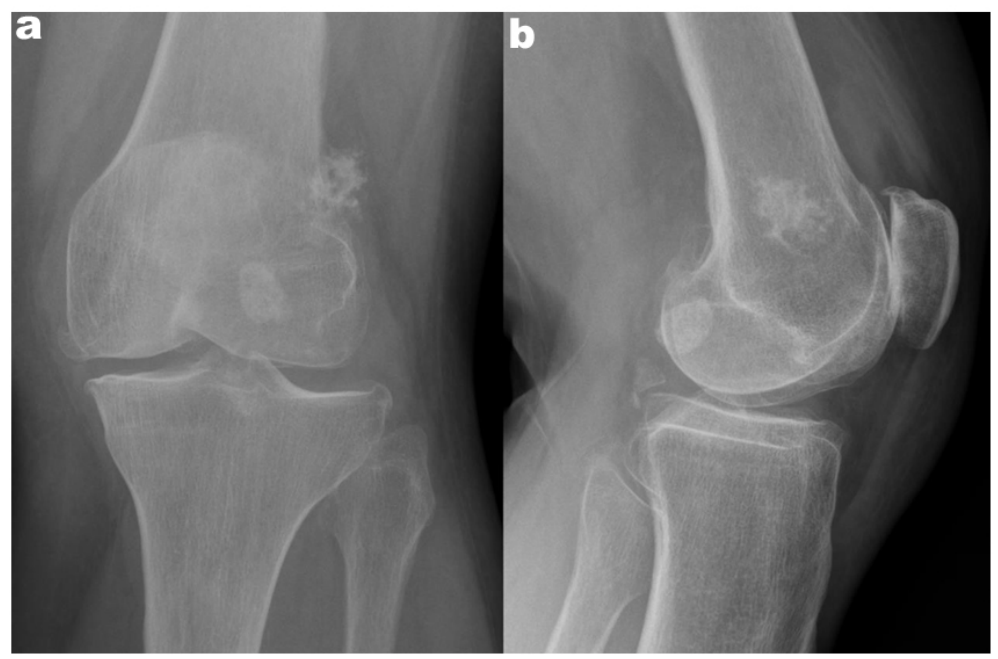

Figure 7. MRI images in sagittal T1 (a) and sagittal (b) and axial (c) PD FS weighted sequences showed a low- intensity calcified mass localized in extra-synovial space (white arrows)

\subsection{Case 4}

A 58 years old female patient presented to the Department of Orthopedics, complaining of persistent pain and dysesthesia on the anterior aspect of distal humerus. She had a history of multiple surgical interventions as carpal tunnel release, rotator cuff repair and radial and ulnar nerve neurolyse. On physical examination, in addition of a hyperhidrose palmaire and a diffuse pain of the forearm at the palpation, the extern rotation of the elbow was limited at $30^{\circ}$. Ultrasonography shows a hypoechoic intramuscular mass of $8 \mathrm{~mm} \times 6 \mathrm{~mm} \times$ $10 \mathrm{~mm}$ in the medial side of the brachialis muscle, facing the

\section{DiscuSsion}

Synovial osteochondromatosis is a rare and benign condition but occasionally it is locally aggressive and around $2.5 \%$ of cases may be subject to transformation to chondrosarcoma. ${ }^{[5]}$ Intra-articular synovial osteochondromatosis usually occurs in young men, in contrast with the extra-articular synovial chondromatosis, which has no age or gender predilection. ${ }^{[6]}$ Two types of synovial osteochondromatosis are recognized: primary and secondary forms. The primary form is correlated with osteochondral loose bodies from benign reactive

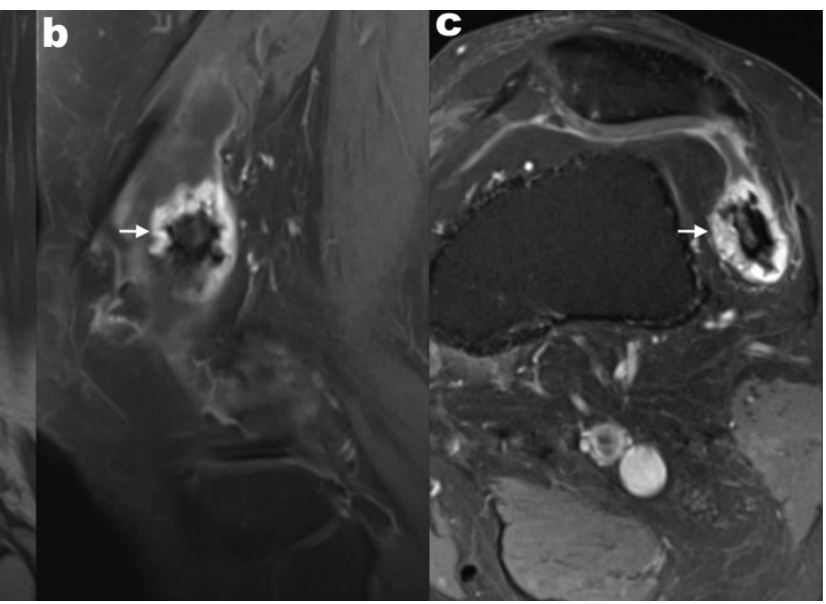

medial humeral epicondyle. No hypervascularisation was noticed inside of the mass. CT showed a slight hyperdense intramuscular mass without osteogenic matrix (see Figure 8). Magnetic resonance imaging (MRI) was performed to characterize the mass. It had an evident hyper-intense aspect in T2-SPIR-weighted images and slightly hyper-intense compared to the muscles in T1- and DP-weighted images. A hypo-intense peripheral ring was evident in all sequences. No Gadolinium enhancement was shown (see Figure 9). The cartilaginous component suggests an extra-articular chondrome. A surgical excision is planned.

metaplasia of the synovial membrane. ${ }^{[7]}$ Primary synovial osteochondromatosis is divided into three phases by Milgram. Phase 1 is characterized by an active synovial disease without presence of loose bodies. Phase 2 is a transitional phase, defined by osteochondral nodules in the synovial membrane and loose bodies in the joint space. Phase 3 shows multiple free osteochondral nodules with a non-active intra-synovial disease. ${ }^{[3]}$ In another hand, Eideken described 4 phases, including the fusion and the coalescence of multiple synovial osteochondromas in a one mass in the intra or extra-articular 


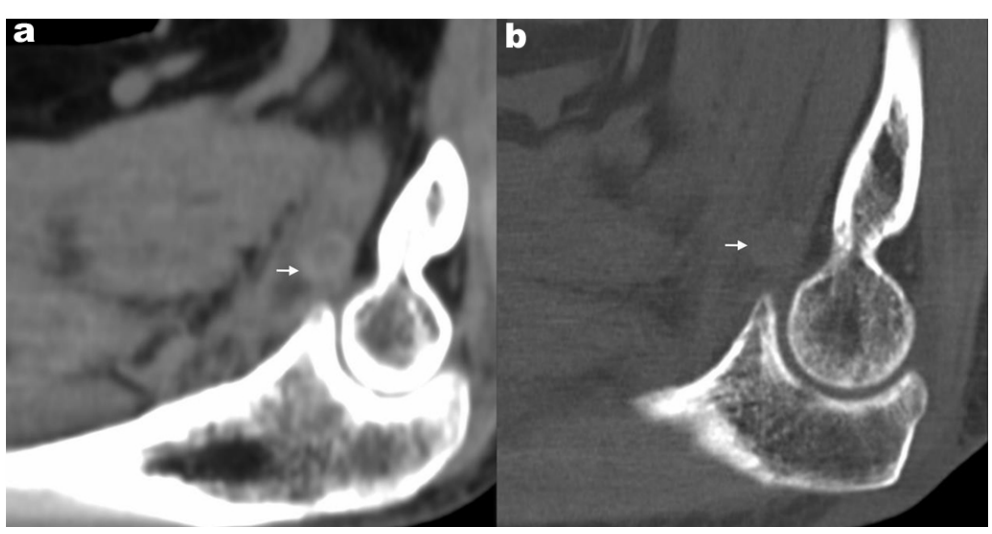

Figure 8. Sagittal CT in soft tissue (a) and bone (b) reconstructions showed a slight dense rounded mass in brachialis muscle (white arrows)

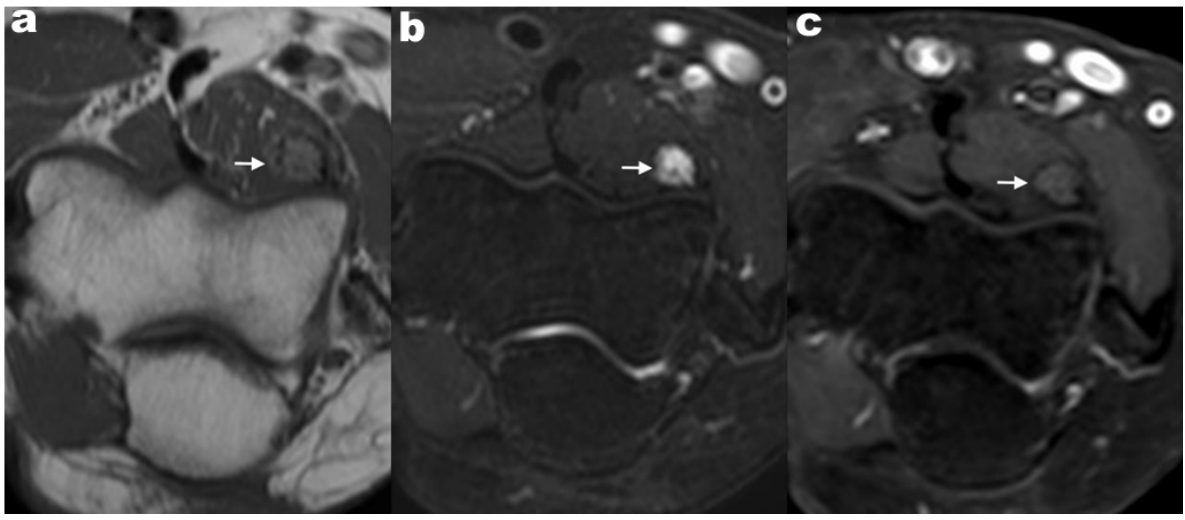

Figure 9. MRI in axial images showed a slight hyperintense mass in $\mathrm{T} 1(\mathrm{a})$, hyperintense in PD (b) without enhancement after administration of Gadolinium (c)

space. ${ }^{[8]}$ Secondary synovial osteochondromatosis is associated with osteoarthritis, synovitis, osteochondritis dissecans, tuberculosis, trauma, rheumatoid arthritis and neuropathic arthropathy. Histopathology shows characteristic differences between primary and secondary form. In the former one, cartilage bodies are composed of calcifications and metaplastic cartilage with binucleated cells. In latter form, cartilage bodies are band like constituted by uniform chondrocytes and fragments of subchondral bone or articular cartilage. ${ }^{[9]}$ Clinically, the patient presents a swollen and a palpable mass progressing in size and resulting in stiffness, pain and motion's limitation of the affected joint. Degenerative osteoarthritis was reported with disintegration of the articular cartilage from multiple intra-articular loose bodies. ${ }^{[10]}$ Routine $\mathrm{x}$ rays, show a soft tissue mass with multiple calcified bodies. In extra-articular osteochondromatosis, the mass can be contiguous to a joint or at a variable distance when localized in bursa or tendon sheath. ${ }^{[5]}$ The sensitivity of radiographic detection depends on the size of cartilaginous nodules. CT is more sensible for the localization of mass and more reliable for the relationship with joints. ${ }^{[11]} \mathrm{CT}$ shows an irregular mixed dense mass associated with punctate and ringed calcifications. MRI is helpful when mass is not calcified and not visible on radiographies. MRI is able to detect cartilaginous mass in initial phase with a specific high intensity on T2. MRI is effective in soft tissue analysis and allows precise location of extra-articular mass in both bursa and tendons sheath. ${ }^{[12]}$ Furthermore, in primary osteochondromatosis, MRI is advantageous to assess the integrity of ligaments and the adjacent articular cartilage. The treatment of choice is surgical excision. It permits to relieve pain and to prevent malignant transformation. Calcified bodies are removed and extensive

synovectomy should be performed to prevent recurrence. In addition, early surgical excision can help to prevent either osteoarthritis. 12 Post-operative follow-up is recommended to reduce the rate of malignant degeneration and recurrence. Recurrence is reported to be of $15 \%$ according to Davis et al. and of $11 \%$ according to Maurice et al. ${ }^{[13]}$ Recurrence may be associated to incomplete excision of the cartilage bodies or persisting of reactive synovial metaplasia. Malignant transformation into chondrosarcome is rare but it can occur with an incidence of 5\%-6\%. ${ }^{[13]}$

\section{Conclusion}

The cases reported provide familiarity with imaging characteristics of uncommon localizations in extra-articular chondromatosis.

\section{CONFLICTS OF INTEREST Disclosure}

The authors declare that there is no conflict of interest statement. 


\section{REFERENCES}

[1] Burrafato V, Campanacci DA, Franchi A, et al. Synovial chondromatosis in a lumbar apophyseal joint. Skeletal Radiol. 1998; 27: 385387. PMid:9730330. https ://doi .org/10.1007/s0025600504

[2] Birchall D, Khangure MS, Spagnolo DV. Vertebral synovial osteochondromatosis with compressive myelopathy. Spine (Phila Pa 1976) 1999; 24: 921-923. https://doi.org/10.14245/kjs.2016.13 .4 .196

[3] Kim DH, Lee EH, Cho ES, et al. Temporomandibular joint synovial chondromatosis extending to the temporal bone: a report of two cases. J Korean Assoc Oral Maxillofac Surg. 2017 Oct; 43(5): 336-342. PMid:29142869. https ://doi.org/10.5125/jkaoms. 2017.43 .5 .336

[4] Bhardwaj A, Raichandani K, Jain H, et al. Giant extraskeletal osteochondroma of foot. A case report with review of literature. Journal of Clinical Orthopaedics \& Trauma. 2017; 8: S78-S81. http://dx.doi.org/10.1016/j.jcot.2017.09.016

[5] Sakamoto A, Naka T, Shiba E, et al. Extra-Articular Tenosynovial Chondromatosis of the Finger: A Case Series Study of Three Cases, One Including Excessive Osseous Invasion. The Open Orthopaedics Journal. 2017; 11: 417-423. PMid:28603573. http: //doi.org/10.2174/1874325001711010417

[6] Karlin CA, De Smet AA, Neff J, et al. The variable manifestations of extraarticular synovial chondromatosis. AJR. 1981; 137: 731-735. PMid:6974968. http://doi.org/10.2214/ajr.137.4.731
[7] Villacin AB, Brigham LN, Bullough PG. Primary and secondary synovial chondrometaplasia: Histopathologic and clinicoradiologic differences. Hum Pathol. 1979; 10: 439-451. PMid:468226. https : //doi.org/10.1016/S0046-8177(79)80050-7

[8] Edeiken J, Edeiken BS, Ayala AG, et al. Giant solitary synovial chondromatosis. Skeletal Radiol. 1994; 23(1): 23-9. PMid:8160032. https://doi.org/10.1007/BF00203697

[9] Chen A, Shih SL, Chen BF, et al. Primary synovial osteochondromatosis of the first metatarsophalangeal joint. Skeletal Radiol. 2002; 31: 122-124. PMid:11828337. https://doi.org/10.1007/s002 56.001-0444-1

[10] Lim SJ, Chung HW, Choi YL, et al. Operative treatment of primary synovial osteochondromatosis of the hip. J Bone Joint Surg Am. 2006; 88: 2456-2464. PMid:17079404. https://doi .org/10.2 106/JBJS.F. 00268

[11] DeBenedetti MJ, Schwinn CP. Tenosynovial chondromatosis in the hand. J Bone Joint Surg Am. 1979 Sep; 61(6): 898-903. PMid:479237.

[12] Doral MN, Uzumcugil A, Bozkurt M, et al. Arthroscopic treatment of synovial chondromatosis of the ankle. J Foot Ankle Surg. 2007; 46: 192-195. PMid:17466247. https://doi/org/10.3892/ol.2 015.3746

[13] Davis RI, Hamilton A, Biggart JD. Primary synovial chondromatosis: A clinicopathologic review and assessment of malignant potential. Hum Pathol. 1998; 29: 683-688. https : //doi.org/10.1016/S0 046-8177 (98) $90276-3$ 